\title{
Preliminary Study on Effect of Chemical Composition Alteration on Elastic Recovery and Stress Recovery of Nitrile Gloves
}

\author{
Kai Yang Tan ${ }^{1}$, Siew Wei Phang ${ }^{1 *}$, Chee Kin Phang ${ }^{2}$, Jing Lang $\mathrm{Choh}^{2}$, Ching Pang Goh ${ }^{2}$, \\ Chong Ban Wong ${ }^{2}$, Tiam Ting Tee ${ }^{2,3}$ \\ ${ }^{1}$ School of Engineering, Taylor's University, Subang Jaya, Selangor, Malaysia \\ ${ }^{2}$ Top Glove R\&D Centre, GMP Medicare Sdn Bhd, Factory 25, 41050 Klang, Malaysia \\ ${ }^{3}$ Faculty of Lee Kong Chain Engineering \& Science, UTAR, Malaysia
}

\begin{abstract}
Nitrile gloves are widely used in the medical and automobile field due to its superiority in hypo-allergic component and chemical resistance over natural latex gloves. However, poor elastic recovery of nitrile glove to compressive force also creates an aesthetic issue for customers with high levels of wrinkling after removing from glove box. This paper demonstrates the preliminary study on the varies chemical composition such as crosslinking agents, sulphur and zinc oxide, the accelerator agent added during curing process, and the rubber filler Titanium Dioxide, on the elastic recovery and stress relaxation in nitrile gloves manufacturing. These chemical were studied at different concentration level comparing the high and low level versus the normal production range. Due to the inconsistency in the analysis technique on the surface imaging, the elastic recovery result was unable to be quantified and was not conclusive at this point. The cross linking agents, sulphur and zinc oxide, and the accelerator agent, played a significant role in the mechanical strength of the gloves. Increment of these chemicals result in higher tensile strength, but a reduction in the elasticity of the materials in which causes a lesser elongation at break percentage for the gloves. Both cross-linkers demonstrate different behaviour where higher sulphur content, provide higher stress relaxation (SR\%) yet zinc oxide shows otherwise.
\end{abstract}

\section{Introduction}

Nitrile Butadiene Rubber (NBR) gloves, as commonly known as nitrile gloves, generally manufactured from a synthetic polymer that exhibits rubberlike characteristics such as elasticity and tensile strength when vulcanized [1]. With the increased reports of allergic reactions to natural latex products, NBR gloves are now the highly recommended alternative glove material in the health care industry [2,3]. NBR has excellent oil resistance. However, shows no self-reinforcing effect, as there is no crystallinity, but when used in combination with reinforcing fillers, vulcanises with excellent mechanical properties can be obtained from NBR. Vulcanisation occurs by a chemical agent, such as sulphur or zinc oxide [4]. Studies have shown that both vulcanized nitrile and natural latex gloves are

\footnotetext{
${ }^{1}$ Corresponding author: eunicepsw@gmail.com
} 
comparable or some shown better physical properties in terms of susceptible to material breakdown, chemical resistance and mechanical behaviour [5,6]. This makes nitrile examination glove to mainstay option for medical use.

Physical properties between NBR and NR latex have contrasting difference due to their difference in molecular constituents. Natural latex (NR) rubber generally have superior elasticity, resilience and softness compared to NBR, which in nature has higher stiffness, poor elasticity, poor resilience but better tensile strength $[5,6]$. The unique characteristics of NBR is linked to the presence of Acrylonitrile (ACN) monomer in its structure, increase in ACN content increases polarity of NBR molecule and glass transition temperature ( $\mathrm{Tg}$ ) properties. Although NBR gloves possess better mechanical properties compared to NR gloves, the stiffer and less elastic nature of NBR gloves do bring about several issues. Poor elastic recovery from compressive stress in NBR gloves results in forming surface wrinkles when subjected to compressive force when folded. Besides, the low stress relaxation property of NBR gloves makes it less comfortable for the user.

Sulphur (S) is the most common vulcanizing agent used in the rubber industry, where it provides sulphur cross-links between long chain polymer molecules which would determine the produced glove properties. Zinc Oxide $(\mathrm{ZnO})$ act as a vulcanizing activator where it would enhance cross-linking between polymer chains and form ionic cross linkage between polymer molecules. Addition of $\mathrm{ZnO}$ enhances vulcanizing efficiency and acts as an activator for sulphur crosslinking. Accelerators are also added into NBR latex as vulcanizing catalyst to greatly increase speed of vulcanisation with process taking a much shorter time while reducing the use of sulphur in the system. Composition of these three chemicals involved in rubber curing would hold a crosslink density of produced rubber and subsequently the mechanical properties of produced glove [7]. Titanium Dioxide $\left(\mathrm{TiO}_{2}\right)$ acts as a rubber filler which reinforces rubber structure for better mechanical properties. Preliminary study will be conducted to test significance of composition change of each chemical towards stress relaxation and elastic recovery of produced latex film. Three of the four chemicals with most significant effect will be studied for optimization to obtain resultant latex with best stress relaxation and elastic recovery properties.

This project is a collaboration study between Top Glove Sdn Bhd and Taylor's University to address the two stated issues regarding their nitrile glove product line. Customer feedback on the high degree of wrinkling when removed from glove box, which is aesthetically unpleasing as well as causing inconvenience for customers to "open" the gloves up from wrinkled state. The poor stress relaxation of nitrile gloves makes it less comfortable when donned for long periods as nitrile glove would not conform to the user's hand. Therefore, a glove that has higher stress relaxation properties would experience deformation (loss of stress) over time and conform to shape of user's hand giving a better comfort when worn for long durations. This research studies the effect of the vulcanisation chemical agents such as Sulphur, zinc oxide, vulcanising catalyst (accelerator) and titanium dioxide and their composition in the intention to improve the stress relaxation and elastic recovery properties of the product. 


\section{Methodology}

\subsection{Materials and sample preparation}

\subsubsection{Materials}

All compounding chemicals including coagulant mixture, NBR mixture, accelerators (Brand name and chemical mixture non-disclosed due to production confidentiality), industrial grade vulcanizing agent such as sulphur, zinc oxide, and titanium dioxide were provided by production line. Compounding of the chemicals was done according to the composition shown at section 2.1.2 at the laboratory for 24 hours prior to glove samples dipping.

\subsubsection{Preparation of latex solution and formulations}

Based on the four target chemicals discussed, composition of chemicals was adjusted to extreme highs and lows to test significance of each chemical towards targeted response (stress relaxation and elastic recovery). Table 2.1 shows the composition of chemicals tested at three levels. Medium level composition represents normal phr values used in nitrile glove production. With this variation, a total of nine batches of latex samples were prepared as shown in Table 2.2.

Table 2.1 Phr values used for each chemical for significance test

\begin{tabular}{|l|c|c|c|}
\hline & Normal level (phr) & Low level (phr) & High level (phr) \\
\hline Accelerator & 0.5 & 0.1 & 3.0 \\
\hline Sulphur & 1.5 & 0.2 & 3.0 \\
\hline Zinc Oxide & 1.5 & 0.1 & 5.0 \\
\hline Titanium Dioxide & 1.6 & 0.2 & 3.0 \\
\hline
\end{tabular}

Table 2.2 Phr values for all target chemicals for each batch of variation in single factor preliminary study.

\begin{tabular}{|l|l|c|c|c|c|}
\hline No. & Sample name & $\begin{array}{c}\text { Accelerator } \\
(\mathbf{p h r})\end{array}$ & $\begin{array}{c}\text { Sulphur } \\
(\mathbf{p h r})\end{array}$ & $\begin{array}{c}\mathbf{Z n O} \\
(\mathbf{p h r})\end{array}$ & $\begin{array}{c}\mathbf{T i O}_{\mathbf{2}} \\
(\mathbf{p h r})\end{array}$ \\
\hline $\mathbf{1}$ & Normal & 0.5 & 1.5 & 1.5 & 1.6 \\
\hline $\mathbf{2}$ & High ZnO & 0.5 & 1.5 & $\mathbf{5 . 0}$ & 1.6 \\
\hline $\mathbf{3}$ & Low ZnO & 0.5 & 1.5 & $\mathbf{0 . 1}$ & 1.6 \\
\hline $\mathbf{4}$ & High Sulphur & 0.5 & $\mathbf{3 . 0}$ & 1.5 & 1.6 \\
\hline $\mathbf{5}$ & Low Sulphur & 0.5 & $\mathbf{0 . 2}$ & 1.5 & 1.6 \\
\hline $\mathbf{6}$ & High accelerator & $\mathbf{3 . 0}$ & 1.5 & 1.5 & 1.6 \\
\hline $\mathbf{7}$ & Low accelerator & $\mathbf{0 . 1}$ & 1.5 & 1.5 & 1.6 \\
\hline $\mathbf{8}$ & High $\mathbf{T i O}_{\mathbf{2}}$ & 0.5 & 1.5 & 1.5 & $\mathbf{3 . 0}$ \\
\hline $\mathbf{9}$ & Low $\mathbf{T i O}_{\mathbf{2}}$ & 0.5 & 1.5 & 1.5 & $\mathbf{0 . 2}$ \\
\hline
\end{tabular}

One kg NBR latex solutions were mixed with the chemicals as shown in Table 2.2. The solution was constantly stirred at 600 RPM for 24 hours at room temperature to ensure homogenization of the solution, in order to avoid settlement of high density solid particles. Calculation of weight of each chemical requires individual chemical's parts per hundred (phr) information and Total solid content (TSC\%). The information can be subbed into (Eq. 
1) shown below to calculate chemical weight ( $g$ ) of each individual chemical. Latex weight was calculated based on $1000 \mathrm{~g}$ of final solution.

$$
\text { Chemical weight }(\mathrm{g})=\frac{\text { chemical phr } \times \text { Latex TSC }(\%) \times \text { Latex weight }(\mathrm{g})}{\text { Chemical TSC }}
$$

\subsubsection{Plate-type glove sample preparation}

Coagulant solution was obtained directly from the production and was maintained at $55^{\circ} \mathrm{C}$ on a hotplate. Lab scale plate-type former was used to prepare the samples. The former was heated up to $60^{\circ} \mathrm{C} \pm 2^{\circ} \mathrm{C}$, followed by a dipping at the coagulant solution for about 2 minutes and dried at the $120^{\circ} \mathrm{C}$ for another 2 minutes. The formers were air-cooled to the range of $60-65^{\circ} \mathrm{C}$ and were dipped in the latex solution prepared from section 2.1.2 for 15 seconds followed by a 15 minutes drying at $120^{\circ} \mathrm{C}$.

\subsection{Elastic recovery testing}

At this moment, there is no developed industrial standardized method of measurement of surface wrinkles available. A preliminary testing was carried out via surface imaging with a simple MATLAB ${ }^{\circledR}$ (version R2016b) coding on elastic recovery for thin rubber films. A simple test method was carried out via folding the latex samples (uniformly and random crumping as shown in Fig. 1) followed by adding a $2.5 \mathrm{~kg}$-weight compression on the samples for 18 hours period. The samples were then scanned through a table top scanner and the image were analysed through the MATLAB ${ }^{\circledR}$ coding.
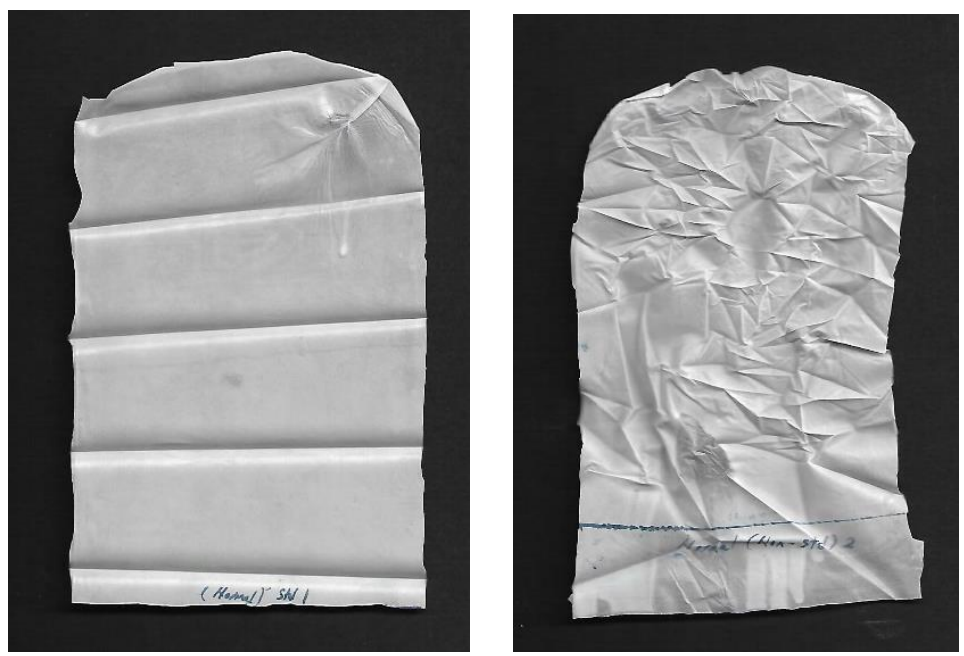

Fig. 1. Standardised folding method (Left) and non-uniform crumpling method (Right)

Surface area selection for wrinkled/folded latex samples were manually adjusted using rectangular box as shown in Fig. 2. Surface imaging analysis was done on area measured $13 \mathrm{~cm}$ from top; where surface below the $13 \mathrm{~cm}$ line was excluded from analysis. The samples were scanned the moment it was removed from the weighted-compression, and were scanned again at an interval of 10 minutes for recovery. Several manual adjustments were required to ensure no surface area outside of the sample was included in analysis, to avoid creating additional analytical error. Image processing using MATLAB ${ }^{\circledR}$ results in contrasting of wrinkled surface (white region) and unwrinkled surface (black region) 
shown in Fig. 2. Wrinkled surface area (white region) over total selected surface was analysed and displayed as wrinkled percentage (\%). Calculation of elastic recovery for 10 minute duration is shown in Equation (2)
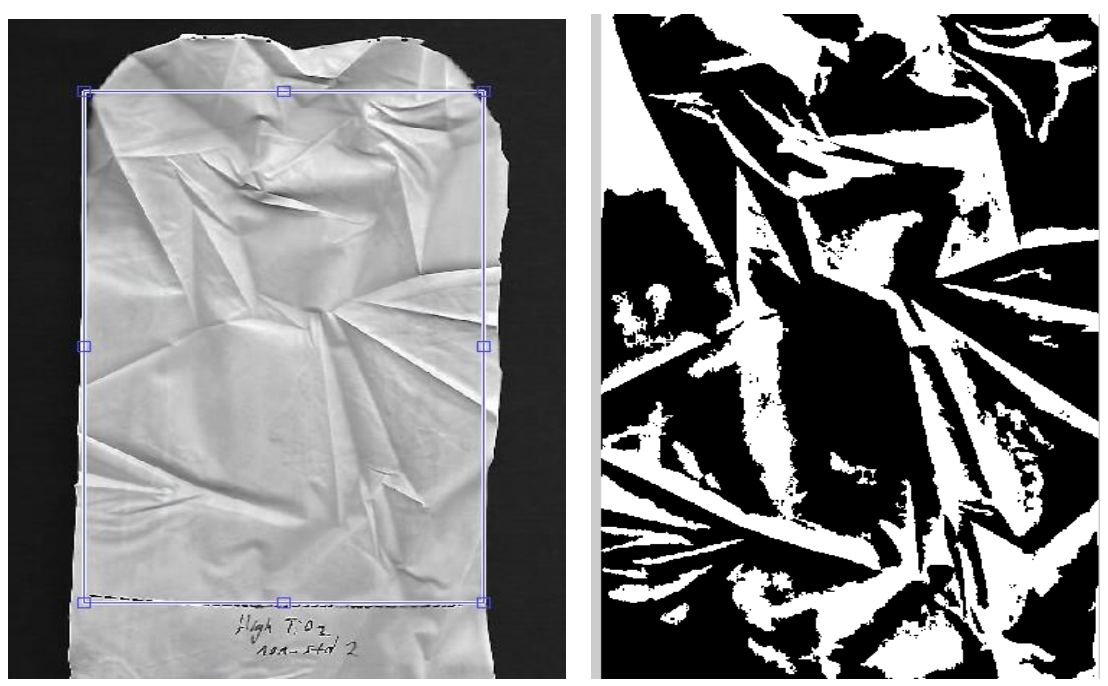

Fig. 2. Selection of analysis area (Blue box) (left) and scanned image (right) for MATLAB ${ }^{\circledR}$

\subsection{Stress relaxation and mechanical property test}

\subsubsection{Preparation of tensile test piece}

All latex test pieces were cut based on ASTM D412 standard as shown in Fig. 3. Dimensions shown are in units of millimetres $(\mathrm{mm})$.

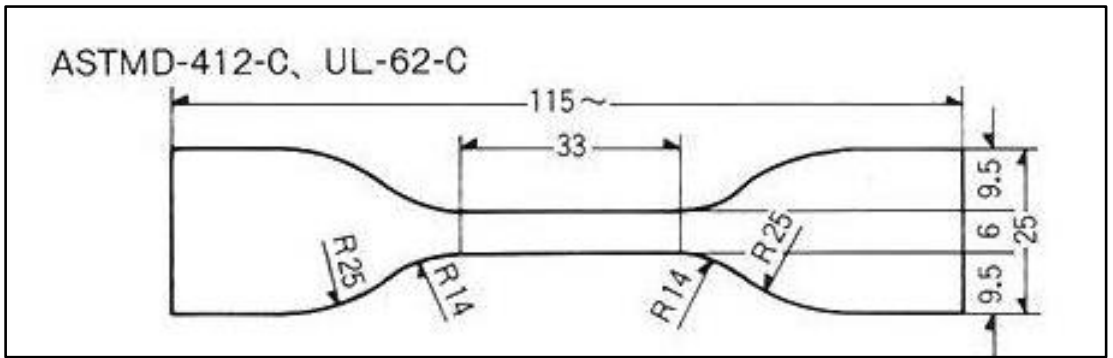

Fig. 3. ASTM D412 Type C die cutter sample

\subsubsection{Tensile strength test}

Dumbbell shaped test samples were gripped on onto clips of the Universal tensile machine (Fig.2). Standard ASTM D882 tensile test before aging standard was used, with upward tension force of $500 \mathrm{~mm} / \mathrm{min}$ set for all test samples. 
Universal tensile machine was used for conducting stress relaxation. Samples were gripped at both ends to clips on the test machine and elongated upwards for a length of $25.414 \mathrm{~mm}$. Samples were left in elongated state for 6 minutes. Stress decay of samples throughout 6 minutes with initial stress and final stress values were recorded in test report with calculated Stress recovery (\%). Eq. 3 shows the formula of calculation for stress relaxation $(\%)$.

$$
\text { Stress Relaxation }(\%)=\frac{F o-F t}{F o} \times 100 \%
$$

where,

$$
\begin{aligned}
& \boldsymbol{F o}=\text { Initial stress value at } \mathrm{t}=0 \\
& \boldsymbol{F t}=\text { Stres value after certain duration, } \mathrm{t}
\end{aligned}
$$

\section{Results and Discussion}

\subsection{Elastic Recovery}

Table 3.1 shows the elastic recovery (\%) of latex films measured at $t=0$ and $t=10$ minutes for both standardized and non-standard folding method. Unfortunately, the outcome of this testing were inconclusive due to high experimental errors caused by inconsistency in manual adjustment of the scanned area. Although the calculated recovery $\%$ was not able to differentiate elastic recovery in 10 minutes, but the minor differences can be seen through visual judgement based on scanned images as shown in Fig 4. It was observed that there are certain amounts of recovery in wrinkling depth between both samples. The scanned image after $t=10$-minute of recovery (right) shows a larger surface area compared to sample image at $t=0$-minute due to the minor elastic recovery in wrinkle depth, causing latex sample to slightly "expand" in size as it recovers. Although the samples displayed a higher degree of elastic recovery after a long period of time, but that defeat the purpose as end users desired a fast recovery of the product as soon as it is immediately removed from glove box.

Table 3.1 Elastic recovery percent of latex film for different folding method.

\begin{tabular}{|l|c|c|c|c|c|c|}
\hline & \multicolumn{7}{|c|}{ Wrinkle percentage \% } \\
\hline \multirow{2}{*}{ Sample Name } & \multicolumn{7}{|c|}{ Standard folding } & \multicolumn{3}{c|}{ non-standard folding } \\
\cline { 2 - 7 } & $\boldsymbol{t}=\mathbf{0}$ & $\boldsymbol{t}=\mathbf{1 0}$ & $\mathbf{R e c o v e r y \%}$ & $\boldsymbol{t}=\mathbf{0}$ & $\boldsymbol{t}=\mathbf{1 0}$ & Recovery\% \\
\hline High Sulphur 1 & 34.27 & 26.34 & 7.9279 & 34.14 & 40.38 & error \\
\hline High Sulphur 2 & 53.98 & 54.10 & error & 54.27 & 53.58 & 0.6939 \\
\hline High Sulphur 3 & 30.54 & 31.51 & error & 44.30 & 44.77 & error \\
\hline High Sulphur 4 & 16.75 & 22.13 & error & 54.68 & 50.44 & 4.2341 \\
\hline Low Sulphur 1 & 51.03 & 57.83 & error & 45.92 & 45.14 & 0.7731 \\
\hline Low Sulphur 2 & 51.33 & 52.93 & error & 46.70 & 46.89 & error \\
\hline Low Sulphur 3 & 38.07 & 32.78 & 5.2911 & 47.12 & 46.16 & 0.9601 \\
\hline Low Sulphur 4 & 30.05 & 25.89 & 4.1584 & 39.07 & 39.13 & error \\
\hline
\end{tabular}




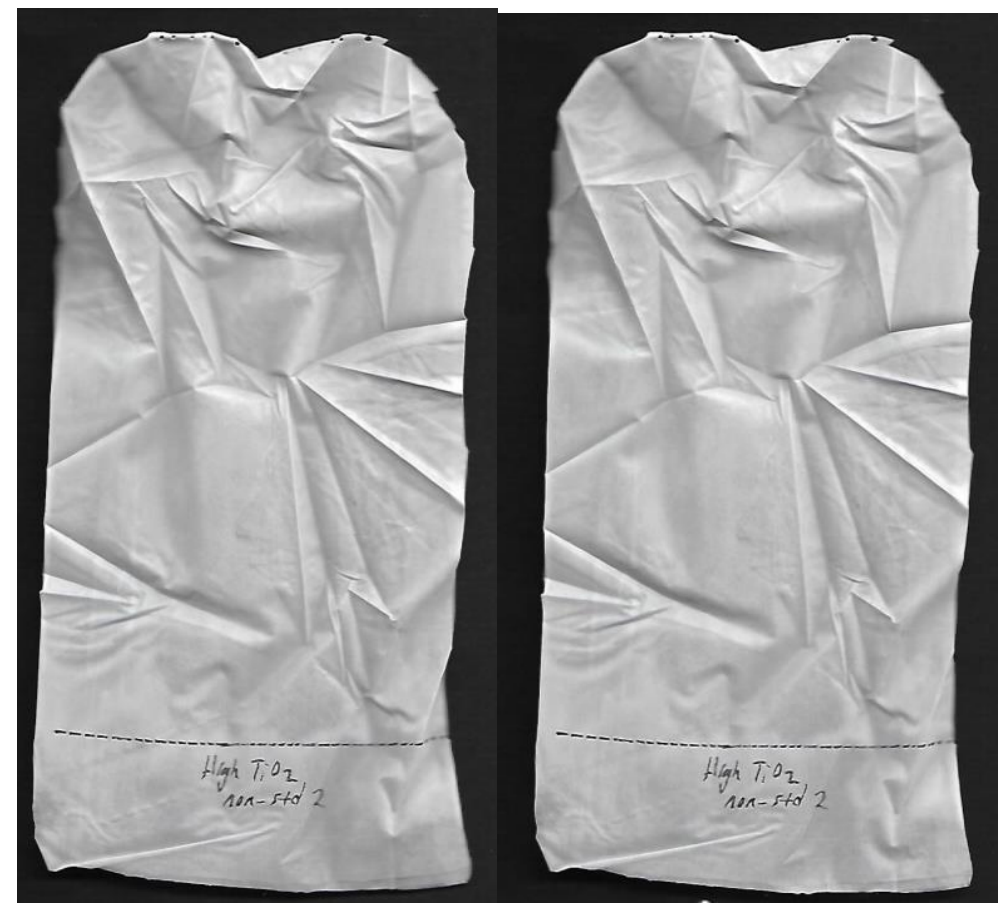

Fig. 4 Scanned images of latex surface at $t=0$ minutes (left) and $t=10$ minutes (right)

There were some limitations in the MATLAB ${ }^{\circledR}$ analysis coding, as it was only able to contrast wrinkled (white) and unwrinkled regions (black) as shown in Fig. 2. The calculation was simulated on estimating the total surface area of wrinkled regions (white) over total selected surface area. But based on visual observation shown in Fig. 4, regions of wrinkle lines and regions remains largely the same for samples at 0 -minute and 10-minute; yet a change in depth of wrinkles was observed. At this moment, the coding created was not able to distinguish the differences at depths, hence creating insignificant results.

Besides the coding limitation, huge error due to inconsistency on manual adjustment for selected surface area was observed. The repeatability of the scanning surface selection was questionable, that creates most invalid data in Table 3.1. Future improvements in coding to automatically fixed or to select area of scanning and improvement in depth analysis will significantly improve this preliminary scanning test method.

\subsection{Significance test for stress relaxation and mechanical strength}

As a preliminary study to select the most influencing chemicals for production optimization, the vulcanising agents concentration were tested at an extreme condition as shown in Table 2.1. Table 3.2 provides the result in stress relaxation (\%) for each chemical variation. All data shown for stress relaxation and tensile strength were averaged out between data obtained from 4 test samples of the same composition batch. Table 3.3 below shows the tensile strength, elongation at break (\%) and elastic modulus at $300 \%$ elongation data for the same samples. 
Table 3.2 Stress relaxation (\%) after 6 minutes of constant strain

\begin{tabular}{|c|c|c|c|c|}
\hline & $\begin{array}{l}\text { Stress at } 0 \text { min, } \\
\text { Fo }(\mathrm{MPa})\end{array}$ & $\begin{array}{l}\text { Stress after } 6 \\
\text { min, } F t(\mathrm{MPa})\end{array}$ & $\begin{array}{c}\text { Stress Relaxation } \\
(\%)\end{array}$ & $\begin{array}{c}\text { Difference } \\
(\%)\end{array}$ \\
\hline High Sulphur & 1.861 & 0.856 & 42.58 & \multirow[b]{2}{*}{3.40} \\
\hline Low Sulphur & 1.696 & 0.722 & 45.98 & \\
\hline High $\mathrm{TiO}_{2}$ & 1.664 & 0.734 & 44.10 & \multirow{2}{*}{0.47} \\
\hline Low $\mathrm{TiO}_{2}$ & 1.405 & 0.626 & 44.57 & \\
\hline High Accelerator & 1.708 & 0.789 & 41.38 & \multirow{2}{*}{4.81} \\
\hline Low Accelerator & 1.553 & 0.643 & 46.19 & \\
\hline High Zinc Oxide & 0.921 & 0.338 & 36.76 & \multirow{2}{*}{13.03} \\
\hline Low Zinc Oxide & 0.500 & 0.250 & 4979 & \\
\hline
\end{tabular}

Table 3.3 Tensile strength, Elongation at break(\%) and Elastic modulus result for test samples

\begin{tabular}{|c|c|c|c|c|c|c|}
\hline & $\begin{array}{c}\text { Tensile } \\
\text { Strength } \\
\text { (MPa) }\end{array}$ & $\begin{array}{c}\text { Difference } \\
\text { between } \\
\text { High and } \\
\text { Low } \\
\text { formulation } \\
\text { (MPa) }\end{array}$ & $\begin{array}{c}\text { Elonga } \\
\text { tion at } \\
\text { break } \\
(\%)\end{array}$ & $\begin{array}{c}\text { Differenc } \\
\text { e between } \\
\text { High and } \\
\text { Low } \\
\text { formulati } \\
\text { on }(\%)\end{array}$ & $\begin{array}{c}\text { Modulus } \\
\text { at } 300 \% \\
\text { Elongati } \\
\text { on } \\
\text { (MPa) }\end{array}$ & $\begin{array}{c}\text { Difference } \\
\text { between } \\
\text { High and } \\
\text { Low } \\
\text { formulation } \\
\text { (MPa) }\end{array}$ \\
\hline $\begin{array}{l}\text { High } \\
\text { Sulphur }\end{array}$ & 46.70 & \multirow{2}{*}{23.71} & 460.8 & \multirow{2}{*}{73.9} & 12.05 & \multirow{2}{*}{6.49} \\
\hline $\begin{array}{l}\text { Low } \\
\text { Sulphur }\end{array}$ & 22.99 & & 534.7 & & 5.56 & \\
\hline High $\mathrm{TiO}_{2}$ & 21.44 & \multirow{2}{*}{1.45} & 481.37 & \multirow{2}{*}{26.93} & 6.64 & \multirow{2}{*}{1.18} \\
\hline Low $\mathrm{TiO}_{2}$ & 22.89 & & 508.3 & & 5.46 & \\
\hline $\begin{array}{l}\text { High } \\
\text { Accelerator }\end{array}$ & 23.62 & \multirow{2}{*}{2.95} & 473.8 & \multirow{2}{*}{94.37} & 7.37 & \multirow{2}{*}{2.42} \\
\hline $\begin{array}{l}\text { Low } \\
\text { Accelerator }\end{array}$ & 20.67 & & 568.17 & & 4.95 & \\
\hline $\begin{array}{l}\text { High Zinc } \\
\text { Oxide }\end{array}$ & 24.60 & \multirow{2}{*}{8.18} & 304.37 & \multirow{2}{*}{213.68} & 22.17 & \multirow{2}{*}{20.08} \\
\hline $\begin{array}{l}\text { Low Zinc } \\
\text { Oxide }\end{array}$ & 14.19 & & 518.05 & & 2.09 & \\
\hline
\end{tabular}

Titanium dioxide $\left(\mathrm{TiO}_{2}\right)$ that acts as reinforcement filler, has not demonstrated a significant effect in stress relaxation (\%). The insignificant difference for high and low samples of $\mathrm{TiO}_{2}$ in stress relaxation (\%) can be backed up by mechanical test data shown in Table 3.3, which shows the least difference across the board for tensile strength, elongation at break (\%) and elastic modulus at 300\% elongation. However, the other three vulcanising agents were observed to significantly affect the mechanical behaviour of the product. Mainly as they were directly involved in rubber curing process, that affect the crosslink density of produced latex [8]. Data shown in the Table 3.3 further proves that a direct influence in crosslink density can affect mechanical strength and overall stiffness of a latex sample.

An additional observation can be made in Table 3.2, stress relaxation (\%) high and low concentration of Zinc Oxide $(\mathrm{ZnO})$ shows an exceptionally higher difference compared to other chemicals, with difference of $13.30 \%$ in stress relaxation. This may hint that ionic crosslinking in rubber molecules can significantly impact mechanical properties of 
produced rubber, in which, suggested that $\mathrm{ZnO}$ is the most significant factor involved in enhancing stress relaxation in produced latex. By referring to results in Table 3.3, elongation at break (\%) High and low Zinc Oxide samples show the highest difference of $213.68 \%$ between samples from both batches. The same trend is observed with elastic modulus at $300 \%$ elongation. High $\mathrm{ZnO}$ samples have given a 10x higher elastic modulus comparing to low $\mathrm{ZnO}$ samples. This meant that low $\mathrm{ZnO}$ samples were exceptionally soft, with much lesser load $(\mathrm{N})$ needed to stretch samples to $300 \%$ elongation. A summary between the relationships of mechanical properties is shown in Table 3.4.

Table 3.4 Relationship between mechanical properties in gloves

\begin{tabular}{|l|c|c|c|}
\hline & $\begin{array}{c}\text { Tensile strength } \\
(\mathbf{M P a})\end{array}$ & $\begin{array}{c}\text { Elongation at break } \\
\mathbf{( \% )}\end{array}$ & $\begin{array}{c}\text { Elastic Modulus - } \\
\text { Rubber Stiffness } \\
(\mathbf{M P a})\end{array}$ \\
\hline $\begin{array}{l}\text { Higher Stress } \\
\text { Relaxation (\%) }\end{array}$ & Lower & Higher & Lower Stiffness \\
\hline $\begin{array}{l}\text { Lower Stress } \\
\text { Relaxation (\%) }\end{array}$ & Higher & Lower & Higher Stiffness \\
\hline
\end{tabular}

Results from preliminary study of significance in effect of chemicals can conclude two major statements: Titanium dioxide $\left(\mathrm{TiO}_{2}\right)$ was the least significant chemical towards stress relaxation (\%). It will be excluded for full factorial design and composition optimization. Zinc Oxide $(\mathrm{ZnO})$ is the most significant factor affecting stress relaxation (\%) and overall softness of produced latex.

\subsection{Conclusion}

The preliminary measurement setup for quantifying the glove surface wrinkle has room for improvement, and the current result was inconclusive due to high measurement error on both human and equipment error. The limitation on the analysis coding for detecting surface wrinkle was only able to determine the number of wrinkles / wrinkled regions of selected area but unable to distinguish the depth of surface wrinkles on nitrile latex surface at this moment. Elastic recovery of wrinkled sample had shown recovery in terms of wrinkled depth but little to no recovery from number of wrinkled. Manual selection of analysed surface area also caused huge inconsistency in repeatability of the selected scanned area, resulting in most samples yielding a negative elastic recovery value. Titanium Dioxide $\left(\mathrm{TiO}_{2}\right)$ showed least significant changes for $\mathrm{SR} \%$ and mechanical properties between high-low concentrations and between normal formulation samples. Increment in sulphur and accelerator concentration caused an increment in SR\%, possibly due to increased sulphur crosslinking in samples. But increment of Zinc Oxide caused decrease in SR\% due to ionic crosslinking between rubber molecules. Tensile strength results show an expected outcome with an increment in mechanical strength with higher concentrations of sulphur, accelerator and zinc oxide due to higher density in crosslinking. But enhanced mechanical strength had a resultant effect of decreased elasticity of produced samples, with elongation at break (\%) showing decreased value with higher concentrations. Sulphur, accelerator and Zinc Oxide are chosen for full factorial study for chemical composition optimization for next phase of the study. 


\section{References}

1. A. Rego and L. Roley, Am. J. Infect. Control, 27, 405-410 (1999).

2. N. Chaiear, S. Sadhra, M. Jones, P. Cullinan, I.S. Foulds, and P.S. Burge, Occup. Environ. Med., 58, 386-91 (2001).

3. E. Aldlyami, A. Kulkarni, M.R. Reed, S.D. Muller, and P.F. Partington, J. Arthroplasty, 25, 27-30 (2010).

4. $\quad$ K.F. El-Nemr, Mater. Des., 32, 3361-3369 (2011).

5. M.D. Fisher, V.R. Reddy, F.M. Williams, K.Y. Lin, J.G. Thacker, and R.F. Edlich, J. Emerg. Med., 17, 1011-8 (1999).

6. J. Sawyer and A. Bennett, Ann. Occup. Hyg., 50, 289-296 (2005).

7. Z.Q. Cao, D.G. Wang, C.B. Cong, Y.F. Wang, and Q. Zhou, Tribol. Int., 69, 141149 (2014).

8. J. Tao, Soft nitrile medical gloves having improved glove relaxation properties, US 2002/0193488 A1, (2002). 